\title{
wal-mart e sua estratégia para o varejo norte-americano e internacional
}

\author{
Armando João Dalla Costa \\ Doutor pela Université de la Sorbonne Nouvelle Paris III. Professor no Departamento de Eco- \\ nomia e no Programa de Pós-Graduação Mestrado e Doutorado em Desenvolvimento Econô- \\ mico da UFPR \\ ajdcosta@ufpr.br
}

\section{RESUMO}

Este texto tem como objetivo analisar a história da Wal-Mart, empresa que iniciou suas atividades em Bentonville, pequena vila do sudoeste norte-americano, e acompanhar sua evolução e importância para o desenvolvimento do varejo. Outro aspecto estudado é a participação do fundador da empresa, assim como o dos sucessores. Neste caso, para garantir a sua continuidade, Sam Walton organizou a firma de tal modo que os herdeiros pudessem ocupar os principais postos de comando no Conselho de Administração, enquanto a direção executiva da empresa fosse gerida por executivos profissionais. O texto destaca ainda o planejamento feito pelos diretores para elaborar um plano estratégico de expansão no sentido de ocupar os mercados americano, asiático e europeu. Para continuar sua trajetória de crescimento a firma buscará ser competitiva tanto no mercado interno norte-americano como ocupar cerca de vinte países mais significativos no mundo.

Palavras-chave: Wal-Mart; empresa multinacional; economia industrial; inovações tecnológicas; varejo; internacionalização.

\begin{abstract}
This paper aims to discuss the history of Wall Mart, a firm that began its activities in 1945 in Bentoville, a small town in the American Southwest, and to account for the evolution of its retailer activities. It also intends to discuss the role played by Sam Walton and his successors. In order to be sure that his firms would continue, Walton included many members of the family in the management board, leaving the executive direction to professional managers. The paper seeks to explain how the new direction of Wall Mart implemented a well-planned strategy of expansion in the American, Asian and European markets. By doing so, does it not only become a key competitor in the US market, but also secured a strong position in about other twenty countries in the world.
\end{abstract}

Key words: multinational company; industrial economy; technological innovation; retail; internationalization.

Em 1992, quando morreu Sam Walton, fundador da Wal-Mart, a empresa faturava US $\$ 43$ bilhões. Em 2003, o faturamento passou para US $\$ 256$ bilhões, com um crescimento de $595 \%$. Apesar disto, há muito 
espaço a ser ocupado. Lee Scott, CEO, principal dirigente administrativo da empresa, lembra que "basta comparar nossa participação no mercado (7,9\% nos Estados Unidos), com a de muitas empresas que conquistaram fatias de 35 a 40\% de vendas" (Slater, 2003:235). Portanto, restam $92,1 \%$ do mercado americano a serem disputados com os concorrentes. "Ainda temos muito espaço na periferia das grandes metrópoles. Você verá que continuaremos salpicando lojas nos subúrbios", lembra o dirigente. Apesar de estar presente em dez países, abrindo novas lojas e comprando concorrentes, "ainda não estamos na França, Itália, Espanha e Turquia, só para citar alguns mercados", menciona o principal executivo do grupo.

O crescimento no mercado americano e a velocidade da expansão internacional, assim como suas práticas administrativas, põem a WalMart em destaque e a tornam objeto de estudo de cientistas de diferentes áreas. No dia 12 de abril de 2004, mais de 250 sociólogos, antropólogos, historiadores e outros pesquisadores reuniram-se na Universidade da Califórnia, em Santa Bárbara para examinar a Wal-Mart em busca de idéias sobre a natureza básica da cultura capitalista americana. O professor de história Nelson Lichtenstein, da Universidade sede e organizador do evento, lembrou que em cada época histórica existe uma empresa prototípica. No século XIX era a Pennsylvania Railroad que ditava as normas; no início do século XX era a Ford; em meados do século foi a vez da General Motors e no final era a Microsoft. Agora, no início do século XXI, "a Wal-Mart altera o zoneamento de cidades americanas, estabelece padrões de salário e até mesmo conduz negociações diplomáticas com outros países" (Greenhouse, 2004:A28).

Para entender esta história, buscou-se analisar a importância do fundador, Samuel Moore Walton (conhecido como Sam Walton) desde 1945 até sua morte. Destaca-se sua capacidade de analisar, conhecer, visitar, buscar inovações entre os concorrentes e adaptá-las para suas lojas. Iniciou como franqueado de grandes empresas americanas de comércio de variedades, até fundar sua própria rede de supermercados. A estratégia adotada foi de atuar a partir de pequenas cidades do interior e nos subúrbios dos grandes centros. Antes de sua morte a WalMart estava presente em quase todos os estados americanos, além de ter iniciado seu processo de internacionalização.

Foi decisivo para sua continuidade a maneira como o fundador conduziu a própria sucessão. Como o crescimento aconteceu de maneira muito rápida, precisou cercar-se de uma quantidade crescente de novos dirigentes, entre os quais buscou incentivar a disputa e possibilitar 
a ascensão profissional. Ainda em 1988 nomeou um CEO, dentre os profissionais da empresa, para assumir o seu lugar na condução dos negócios. Ele e seu filho mais velho, o único que atuava na empresa, passaram a ocupar os principais cargos no Conselho de Administração. No momento de sua morte, esta estrutura foi mantida. Robson Walton permaneceu como chairman, maior posto no Conselho Administrativo e David Glass continuou como o CEO, principal posto na Direção Executiva dos negócios, caracterizando a Wal-Mart como um misto de administração profissional e familiar.

Os dirigentes que sucederam o fundador tiveram papel decisivo na implementação de novos formatos de lojas, adequados ao perfil dos consumidores e ao local de sua implantação, assim como fortaleceram o setor de gêneros alimentícios. Também foi fundamental preparar o grande arsenal de informações e o sistema logístico, assim como a estruturação da burocracia administrativa, que puderam garantir o forte crescimento da empresa.

Apontada ainda pelo fundador como a direção futura, a internacionalização ganhou mais espaço e investimentos com a nova equipe administrativa. Passada uma década de sua morte, a empresajá estava presente nas Américas, na Ásia e na Europa.

A fundamentação teórica em que se baseia o texto, segue os pensadores da industrialização, focando a contribuição de Alfred Chandler (1972), que analisa as empresas a partir de suas reestruturações internas, administrativas, tecnológicas e de organização do trabalho, para enfrentar os desafios do crescimento e da internacionalização. Suas principais contribuições teóricas a respeito da história empresarial foram reunidas em Chandler (1998), Ensaios para uma teoria histórica da grande empre$s a$, onde constam as análises elaboradas para a construção dos principais textos do autor.

No que se refere às empresas familiares, seguiram-se basicamente os textos de Gersick et. al. (1997), ao tratar das empresas familiares de modo geral e, especificamente, da passagem do poder entre a geração do fundador e a dos sucessores. Para o mesmo tipo de problemática há muitas referências na literatura brasileira, dentre as quais destacamos Martins et. al. (1999), que analisam o perfil e as perspectivas das empresas familiares brasileiras.

A respeito das fontes, utilizou-se a biografia do fundador (Walton, 1993), que permite recuperar os principais dados e datas, destacando a evolução da empresa desde a época do comércio de variedades, a fundação da Wal-Mart, até o início da década de 1990. Na seqüência, utili- 
zou-se o texto de Slater (2003) que se propõe relatar a contribuição da equipe pós-Walton no grande crescimento da firma nesta última década.

Também foram de fundamental importância as informações da Internet, não só do site oficial da empresa nos EUA, onde se encontra a maior parte das informações (inclusive os relatórios anuais), como também os sites dos respectivos países de atuação da Wal-Mart internacional.

\section{Sam Walton, Wal-Mart e a revolução no varejo norte-americano}

Antes de construir a Wal-Mart, Sam Walton promoveu uma verdadeira revolução no varejo e exerceu um longo aprendizado de comerciante. Sam nasceu em Kingfischer, Oklahoma, em 1918, filho de Thomas Gibson Walton,

(...) um personagem que gostava de fazer trocas, de negociar com qualquer coisa: cavalos, mulas, gado, casas, fazendas, carros. Foi o melhor negociador que conheci. Exerceu todos os tipos de atividades: banqueiro, fazendeiro, avaliador de fazendas, corretor de seguros e de imóveis (Walton, 1993:3).

Formou-se em Comércio, na Universidade de Missouri, em 1940 e, logo em seguida, aceitou emprego na J. C.Penney, cadeia de lojas de miudezas, em Iowa, onde começou sua carreira de comerciante, trabalhando durante 18 meses, até os EUA entrarem na guerra. Ao ingressar no exército, Sam tinha certeza de duas coisas: sabia que se casaria com Helen' e que trabalharia no varejo para ganhar a vida. Em 1945, após a

O casal teve quatro filhos:Robson, nascido em 28 de outubro de 1944-John (1946), Jim (1948) e Alice (1949). Robson formou-se em Direito, tornou-se o primeiro advogado da Wal-Mart e participou da alta administração da companhia a partir de 1978. John T. Walton é administrador de imóveis, dirige as Empresas Walton e, a partir da morte do pai, em 1992, faz parte da direção da Wal-Mart. Jim e Alice trabalharam algum tempo na Wal-Mart, mas acabaram abrindo negócios próprios. Jim projeta e faz barcos à vela e dirige uma grande companhia de pulverização de plantações, propriedade das Empresas Walton. Sam morreu no dia 5 de abril de 1992 e Helen (nascida em 1919), junto com os filhos, detêm $38 \%$ das ações da WalMart (Walton, 1993 e Slater, 2003). 
guerra, decidiu ter seu próprio negócio. Helen concordou, mas impôs duas condições. Uma era a de que ele não deveria ter sócios e a segunda, que iria acompanhá-lo em qualquer lugar, desde que a cidade não tivesse mais que dez mil habitantes.

Em $1^{\circ}$ de setembro de 1945 , inaugurou sua loja de franquia da cadeia Bem Franklin, especializada em lojas de miudezas, em Arkansas. Foi ali, conhecendo seus concorrentes e colocando em prática as compras diretas dos produtores e vendas por preços baixos que Sam exerceu seu aprendizado de comerciante. Após cinco anos, com o vencimento do aluguel, foi obrigado a vender a loja, mudando-se para Fayetteville, em 1952, onde comprou a Walton's Five \& Dime. Em seguida, associando-se com o pai e o irmão Bud e seus dois cunhados (Nick e Frank), abriu lojas em Little Rock, Springdale e Siloam Springs, no Arkansas, além de outras em Neodesha e Coffeyville. "Num prazo de 15 anos passamos a ser a maior empresa independente de lojas de miudezas nos Estados Unidos. Em 1960, estávamos fazendo US\$1,4 milhão em 15 lojas" (Walton, 1993:38).

O grupo crescia, mas o resultado líquido não era satisfatório. Por isto, Sam e seus executivos, buscando uma alternativa mais rentável e lucrativa, interessaram-se pelos supermercados. Na época, o auto-serviço expandia-se nos EUA, o que levou os novos empreendedores a experimentarem esta inovadora forma de varejo.

Em 2 de julho de 1962, inaugurou-se a primeira loja Wal-Mart', em Rogers. Passados dois anos, foram abertas outras duas, em Springdale e em Harrison. "Em princípios da década de 1960 tínhamos 18 lojas de miudezas, sob os nomes de Bem Franklin e Walton e um punhado de Wal-Marts. As lojas de miudezas, aos poucos, foram substituídas por Wal-Marts" (Walton, 1993:48).

A década de 1960 foi de aprendizado no varejo e de consolidação no novo ramo de supermercados. Entretanto, para uma pequena empresa do sudoeste americano, baseada em pequenas cidades e pouco conhecida dos fornecedores e do mercado financeiro, ficava difícil conseguir recursos, o crescimento era limitado e o endividamento cada vez mais forte.

O nome Wal-Mart surgiu numa conversa entre Sam Walton e Bob Bogle, primeiro gerente da Waltons Five \& Dime, numa viagem de avião. Bob sugeriu Wal, de Walton e Mart, que significa lugar de fazer compras, em escocês (Walton, 1993: 40). 
Em 1970, a empresa tinha 78 sócios, um total de 32 lojas, cada uma representando uma combinação diferente de capital entre diversos investidores. A família Walton era a maior acionista, mas Sam e Helen estavam muito endividados. Para sair do endividamento, resolveram transformar a Wal-Mart em sociedade anônima. O primeiro lote de 300.000 ações foi vendido em $1^{\circ}$ de outubro de 1970 , a US $\$ 16,50$ cada, para cerca de 800 acionistas, arrecadando US\$4,95 milhões.

A família Walton ficou com $61 \%$ da Wal-Mart, mas pudemos pagar a todos os banqueiros e, a partir de então não tomamos um tostão emprestado, pessoalmente, para manter a empresa. A abertura do capital ${ }^{3}$ realmente liberou a empresa para crescer e tirou dos meus ombros um grande peso (Walton, 1993:89).

Tabela 1 - Wal-Mart e a ocupação do território americano - 1962-1995

\begin{tabular}{lcl}
\hline Anos & $\begin{array}{c}\text { Estados } \\
\text { com lojas }\end{array}$ & Estados inaugurando lojas nos respectivos anos \\
\hline 1962 & 1 & Arkansas \\
1971 & 5 & Louisiana, Missouri, Oklahoma \\
1973 & 6 & Tennessee \\
1979 & 11 & Alabama \\
1982 & 15 & Flórida, Nebraska \\
1983 & 19 & Indiana, Iowa, Novo México, Carolina do Norte \\
1984 & 20 & Virginia \\
1985 & 22 & Wisconsin, Colorado \\
1986 & 23 & Minesota \\
1990 & 34 & Califórnia, Nevada, Dakota do Norte, Dakota do Sul, Pensilvânia, Utah \\
1991 & 42 & Connecticut, Nova Hampshire, Nova Gersey, Delaware, Maine, Mariland, \\
& & Nova York \\
1992 & 45 & Idaho, Montam, Oregon - Porto Rico \\
1993 & 49 & Alaska, Havaí, Rhode Island, Washington \\
1995 & 50 & Vermont \\
\hline
\end{tabular}

Fonte: http://www.wal-mart.com.ar Acesso: 13 ago. 2004.

Para que os investidores se dispusessem a deixar Wall Street e acompanhar as reuniões anuais de prestações de contas em Fayetteville, estas foram transformadas em grandes eventos, com a presença de astros do esporte e da mídia. No dia 4 de junho de 2004, aconteceu "a maior reunião do Conselho de Administração de uma empresa no mundo, quando 15 mil pessoas se reuniram no estádio BudWalton Arena. A delegação brasileira contou com 160 empregados do Bompreço" (Mattos, 2004: B 12). 
A estratégia para o crescimento acelerado, adotada daquele momento em diante, continuou seguindo a prática anterior. $O$ foco de crescimento se manteve a partir das pequenas cidades. O centro administrativo ficava em Fayetteville, no Arkansas, de onde partiam para ocupar os espaços vizinhos. Cada loja devia ficar, no máximo, a um dia de um centro de distribuição. "Íamos o mais longe possível de um armazém e abríamos uma loja. A partir daí enchíamos o mapa daquele território, estado a estado, condado a condado, até que tivéssemos saturado aquela área de mercado" (Walton, 1993).

Esta estratégia serviu para expandir a empresa para outros estados, mantendo Fayetteville como sede, até que, logo após a morte do fundador, a Wal-Mart atingiu os 50 estados norte-americanos.

Estando o foco de atuação voltado para as pequenas cidades ${ }^{4}$, buscou-se adaptar o tamanho das lojas aos potenciais consumidores de cada local. Adotavam-se cinco tamanhos diferentes, variando entre 2.700 e $3.500 \mathrm{~m}^{2}$ e dificilmente deixavam de lado um mercado por ser pequeno demais.

Como acontece freqüentemente nas empresas familiares, de início Sam acompanhava pessoalmente todos os contratos para aquisição de terrenos e abertura de novas lojas, assim como as tarefas administrativas internas, desde a comercialização, passando pelas operações imobiliárias, estudo da concorrência, financiamentos, contabilidade.

$\mathrm{Na}$ medida em que a empresa crescia, Sam precisava aumentar o número de executivos para ajudá-lo na administração e na expansão das lojas. Uma de suas virtudes foi cercar-se de pessoas competentes para ajudá-lo, que permitiram um crescimento espetacular a partir da década de 1970.

Uma das atividades que dava prazer a Sam era visitar as lojas e conversar com clientes, funcionários e gerentes. Quando a empresa cresceu, manteve este hábito, comprando aviões para facilitar seu deslocamento, mas introduziu a prática de reunir todos os gerentes de lojas e

\footnotetext{
A estratégia das pequenas cidades foi decidida por motivos familiares, pois, com dois anos de casados, Sam e Helen já tinham feito 16 mudanças. Quando Sam decidiu comprar e construir lojas de comércio Helen lhe disse que o acompanharia para qualquer lugar, desde que a cidade não tivesse mais que dez mil habitantes. A partir daí, "sua estratégia básica consistia em lançar boas lojas de desconto em cidades muito pequenas, quase sempre ignoradas por outras cadeias varejistas. A Kmart não entrava em cidades com menos de 50.000 habitantes e a Gibson's evitava cidades com menos de 10.000 habitantes" (Slater, 2003: 107).
} 
os gerentes regionais nas manhãs de sábado. "É nas reuniões das manhãs de sábado que discutimos grande parte de nossa filosofia e de nossa estratégia administrativa: é o ponto focai de todos os nossos esforços de comunicação" (Walton, 1993:148).

Pelo fato de atuarem em pequenas cidades do interior, longe dos grandes centros urbanos e serem uma pequena cadeia de lojas, eram totalmente ignorados por distribuidores e atacadistas. Para contornar este fato, tiveram que organizar seu próprio sistema de distribuição. Além disto, precisavam de produtos de grandes companhias, como a Procter \& Gamble, sendo que estas podiam muito bem vender as próprias mercadorias sem contar com a Wal-Mart.

Buscando resolver seus problemas de fornecimento e a um custo cada vez mais baixo, a partir de 1987 começou uma mudança no relacionamento entre as empresas produtoras e os varejistas. A Wal-Mart propôs uma reunião entre os dez principais dirigentes de sua empresa com os da Procter \& Gamble em Bentonville para dois dias de reflexões. Dentro de três meses tinham criado uma equipe $P \& G$-Wal-Mart para estabelecer um novo relacionamento entre fabricante e varejista. Com a partilha de informações, a $P \& G$ podia monitorar os dados de vendas e estoques da Wal-Mart e usar estas informações para preparar seus planos de produção e embarque de maneira muito mais eficiente.

Se, no início, os fornecedores não tinham interesse em vender seus produtos à Wal-Mart, quando a empresa cresceu esta realidade se inverteu. Ao se tornar a maior distribuidora dos EUA, passou a pressionar os fornecedores para diminuírem constantemente seus preços. Hoje dizse que "nos EUA o poder de barganha da Wal-Mart é temido por todos os fornecedores" (Diniz, 2004:51).

Em sua estratégia de expansão, a Wal-Mart utilizou tanto a construção de lojas como a compra de grupos concorrentes. Neste último caso, as aquisições permitiram um acesso rápido a regiões e mercados em que a empresa não atuava, com o inconveniente de que as novas aquisições deveriam passar pelo processo de incorporação da cultura e modo de organização Wal-Mart. A empresa adotou ambos os métodos, tanto no mercado doméstico como no cenário internacional, a partir do início da década de 1990.

Dentre as aquisições no mercado norte-americano, destacam-se a compra de uma pequena cadeia de lojas de oferta Mohr Value, em Ilionois, realizada por Bud e David Glass em 1977. No processo de adaptação das antigas lojas ao modelo wal-mart, cinco foram fechadas e 16 outras transformadas em Wal-Mart. 
Dando sequiência a esta estratégia, em 1981 a Wal-Mart comprou a Kuhn's Big K, rede de lojas de variedades, que começou em 1920 e possuía 112 lojas concentradas no Tennessee, mas com negócios também em Kentucky, Alabama, Geórgia e Carolina do Sul.

Esta aquisição marcou um novo patamar de expansão. Sobre o total de lojas adquiridas, algumas eram deficitárias e, conseqüentemente, foram fechadas. As demais, aos poucos, foram adequadas à maneira de administração do grupo. Do início da década de 1980 em diante, a WalMart passou a inaugurar mais de 100 lojas por ano.

Tabela 2. Wal-Mart-Lojas, empregados, vendas e lucro - 1962-12003

\begin{tabular}{lrccc}
\hline Ano & Lojas & $\begin{array}{c}\text { Empregados } \\
\text { (em mil) }\end{array}$ & $\begin{array}{c}\text { Vendas } \\
\text { (em US\$ milhões) }\end{array}$ & $\begin{array}{c}\text { Lucro } \\
\text { (em US\$ milhões) }\end{array}$ \\
\hline 1962 & 1 & & & \\
1967 & 24 & & 12,6 & 1,2 \\
1970 & 45 & 7,5 & 30,8 & 40 \\
1975 & 125 & 27 & 236,0 & \\
1980 & 330 & 104 & 1,24 & 1.000 \\
1985 & 882 & 328 & 6,4 & \\
1990 & 1.525 & 675 & 25,8 & \\
1995 & 2.784 & 1.200 & 78,3 & 6.271 \\
2000 & 3.989 & 1.303 & 156,2 & 6,671 \\
2001 & 4.189 & & 180,7 & \\
2002 & 4.6414 & & 204,0 & \\
2003 & 4.688 & 1.600 & 229,6 & \\
2004 & 4.906 & & 256,3 & \\
\hline
\end{tabular}

Fonte: Elaboração do autor a partir do material da empresa.

Talvez a característica mais marcante em Sam Walton tenha sido sua curiosidade e capacidade de analisar e conhecer as melhores práticas de seus concorrentes e adaptá-las a seu negócio.

A Kmart sempre me interessou, desde a primeira loja em 1962. Eu ia constantemente às suas lojas porque eram um laboratório e eles eram melhores do que nós. Passei grande parte do meu tempo andando pelas suas lojas, conversando com seu pessoal e tentando descobrir como faziam as coisas (Walton, 1993:172).

Esta atitude Sam manteve até o final da vida. No início da década de 1980, percorreu a Alemanha, a França, a Itália, a África do Sul, a Grã Bretanha, a Austrália e a América do Sul. Voltou impressionado "com as gigantescas lojas Carrefour no Brasil" (Walton, 1993:180). A partir 
desta observação, decidiu lançar nos EUA os Hypermart, grandes lojas com mercearia e mercadorias em geral sob o mesmo teto. Entretanto, nos EUA os Hypermarts não se mostraram lucrativos o suficiente para se manterem funcionando. A partir desta experiência, a Wal-Mart desenvolveu o conceito dos Supercenters, combinação de mercearia e comercialização em geral, com tamanhos menores que os Hypermart. Este novo modelo de loja foi a base da forte expansão da empresa a partir do início da década de 1990.

No seu processo de crescimento, a Wal-Mart sofria pressões para envolver-se em negócios que não tinham nada a ver com o comércio, como as atividades industriais e serviços financeiros. David Glass afirma que Walton e sua equipe estabeleceram a estratégia de investir apenas no comércio.

Desde cedo assumimos o compromisso de que nunca entraríamos em qualquer área que não fosse a de nosso negócio específico. Sabíamos fazer o que estávamos fazendo e juramos que continuaríamos a fazer a mesma coisa. Tudo estaria bem enquanto a WalMart se mantivesse focada em sua única capacidade essencial, lançando boas lojas uma após a outra (Slater, 2003:70).

Sem abrir mão desta estratégia, a Wal-Mart manteve-se receptiva às novidades e necessidades no comércio. Atualmente, trabalha com diversos formatos de lojas, desde os Sam's Clubs, passando pelas lojas de desconto, supercenters e mercados de vizinhança (tabela 6).

Se os Hypermarts foram abandonados, o mesmo não se pode dizer dos Sam's Clubs. Trata-se de um conceito de loja do tipo armazém, destinado a proprietários de pequenos negócios e outros clientes que compram mercadorias por atacado. A primeira foi inaugurada em 1983 e, nove anos depois, já havia 217, com um faturamento de 10 bilhões de dólares.

Apesar do grande território norte-americano e de disputar o maior mercado do mundo, a Wal-Mart, em tempos de globalização, pensou em ser muito mais que uma empresa local. Sua internacionalização se impôs, na medida em que estava pronta para disputar o mercado mundial. Este foi o desafio que se apresentou na passagem da década de 1980 para a de 1990. O próprio fundador iniciou este processo, apesar de ter centrado suas atenções no mercado americano. No final de sua vida, afirmou "não sei se a Wal-Mart pode manter realmente a nossa posição de liderança ficando apenas nos EUA. Acho que teremos de 
nos transformar numa companhia mais internacional num futuro não muito distante" (Walton, 1993:184).

O crescimento acelerado da empresa a partir dos anos 1980 começou a exigir investimentos e práticas organizativas internas para responder aos novos desafios. Um dos problemas mais sérios era o abastecimento de um número cada vez maior e mais disperso de lojas. Tratava-se de pensar na logística. Neste campo, o principal colaborador foi David Glass, que teve a visão dos centros de distribuição automatizados. Glass empenhou-se na criação deste sistema a partir de 1978, em Searcy, Arkansas. No início dos anos 90 havia 20 centros localizados estrategicamente, de tal forma que as lojas mais distantes ficassem a não mais que 550 quilômetros.

Desde que David Glass foi trabalhar na Wal-Mart, em 1976, empenhou-se em desenvolver a logística, com a colaboração de Jack Shewmaker, encarregado de implantar um sistema de computador cada vez mais avançado para acompanhar as vendas, as mercadorias e os estoques de toda a companhia. Estes sistemas tornavam-se cada vez mais importantes para acompanhar o crescimento da empresa, tanto em lojas, como em vendas e lucros, sempre em expansão desde o início, mas com crescimento acelerado nos anos 1980.

Em abril de 1992, mês da morte de Sam Walton, a Wal-Mart, contava com 371.000 empregados, operava 1.714 lojas e 208 Sam's Clubs, nos Estados Unidos, mas tinha apenas seis supercenters e suas unidades no exterior limitavam-se ao México.

\section{Sucessão, nova equipe de comando e os desafios do crescimento}

A Wal-Mart modificou a lógica das grandes empresas americanas, cujo procedimento era o de pagar bons salários a seus milhões de funcionários para irem às compras como consumidores abastados. Baseado num faturamento anual de US\$256 bilhões, sua contribuição ao ciclo econômico mundial consiste em três itens: pressionar os fornecedores para reduzir custos, usar tecnologia digital de primeira linha para baratear a gestão de seus estoques e, finalmente, pagar aos seus 1,6 milhão de funcionários, o menor salário possível, encolhendo os custos.

Outra forma de manter esta prática é evitar ao máximo a sindicalização de seus funcionários. Para tanto, foi implementada a política de "portas abertas", em que qualquer funcionário pode dirigir-se aos superiores, até mesmo ao CEO. Segundo esta tese, "desde que os empre- 
gados dispusessem de meios para expressar suas insatisfações, reais ou percebidas, nos mais altos níveis da empresa, não haveria razão para recorrerem a pessoas de fora" (Slater, 2003:145).

Como conseqüência, os casos de ações na justiça contra a empresa não param de aumentar. "Em princípios da década de 1990 a empresa era ré em 2.000 a 2.500 processos judiciais, número que chegou a 8.000 em outubro de 2002". Para se defender, a empresa fortaleceu o departamentojurídico, que "cresceu de apenas 20 advogados em 2000, para 90, no outono de 2002" (Slater, 2003:220 e 225).

Parte desta "cultura empresarial" foi herdada do fundador, tendo continuidade e/ou sendo aprofundada pelos sucessores. Quando Sam Walton morreu de câncer em 5 de abril de 1992, uma semana depois de seu $74^{\circ}$ aniversário, o jornal local Benton Country Daily Record, trazia uma declaração de seu filho mais velho, Rob, salientando que não ocorreriam mudanças na direção corporativa ou na política da empresa (Slater, 2003:54).

No início de 1992, Sam Walton já se afastara quase totalmente das atividades operacionais. Uma equipe de gestores profissionais estava atuando, constituída pelo próprio fundador. David Glass vinha realizando um excelente trabalho na direção, à medida que Walton saía de cena, mas a Wal-Mart era cria de Sam Walton: ele a concebera, ele a transformara em potência do varejo e dera o tom da cultura.

O erro de muitas empresas familiares é não transferir o controle para a equipe gerencial que está na condução dos negócios. A decisão dos herdeiros de Walton de manter os principais executivos em seus postos de direção foi fundamental para garantir a tranqüilidade do processo de transferência do poder.

Nos seus últimos meses de vida Sam preocupou-se em encaminhar a própria sucessão. Dispunha de três alternativas. A primeira era buscar alguém fora da companhia. A vantagem é que disporia de um grande pool de executivos talentosos e experientes. A desvantagem é que nenhum destes indivíduos seria tão dedicado à organização e tão familiarizado com a filosofia de negócios e com a cultura organizacional quanto muitos dos executivos seniores da Wal-Mart. Provavelmente por esta razão, demonstrou pouco interesse na busca de sucessores fora da empresa.

A segunda opção era selecionar um membro da equipe de gestores profissionais da Wal-Mart, provavelmente David Glass. Sem dúvida, Walton vinha preparando Glass para uma importante função de liderança e era de se presumir que ele estivesse pronto e disposto para 
preencher a vaga do fundador. A dúvida era quanto à perspectiva de oferecer o posto mais alto da empresa a alguém de fora da família.

A terceira opção era escolher um membro da família. Rob Walton destacava-se como candidato óbvio. Era o único dos filhos que exercera função operacional sênior na Wal-Mart durante um longo período. O pai achava que ele podia representar os interesses da família. Por isto, escolheu seu primogênito para assumir o posto de presidente do conselho de administração depois de sua morte.

Ao decidir por Rob como chairman, sem nomeá-lo CEO, o pai deixou claro que a direção efetiva do dia-a-dia da empresa deveria ficar com um executivo que não pertencesse à família. Uma década depois da morte do fundador, seus herdeiros continuam deixando claro que em nenhum momento tiveram a intenção de questionar ojulgamento do pai. "Tínhamos enorme confiança em sua capacidade de avaliação. Todos conversamos sobre a decisão, mas nenhum de nós jamais pensou em contrapor-se ao que na opinião dele era o melhor para nós", afirmou John (Slater, 2003:88).

Sam começou a preparar David Glass ainda em 1984,.ao nomeá-lo presidente e diretor operacional. Com aquela iniciativa, Walton deixava claro que queria uma gerência profissional à frente do dia-a-dia da empresa. Quatro anos depois, em 1988, Walton cedeu seu próprio posto de CEO a David Glass.

Com exceção de Rob, os demais filhos optaram por rumos fora da empresa. Rob começou a trabalhar em tempo integral na Wal-Mart em 1978, ocupando as posições de vice-presidente sênior, conselheiro, secretário e chefe do departamento jurídico. Diferente do pai, preferia pensar na estratégia geral da empresa, nas propriedades imobiliárias e na expansão internacional a envolver-se com visitas às lojas ou com questões administrativas do dia-a-dia.

Os herdeiros aprovaram este plano de sucessão e o grupo de gestores profissionais, constituído por Walton, ainda hoje é o mesmo.

A equipe de liderança pós-Walton chegou a um acordo não-escrito pelo qual compartilharia e dividiria o poder entre três executivos seniores: Rob Walton, David Glass e Don Soderquist. Mais recentemente, também entraram no grupo Lee Scott e Tom Couglin. Ninguém explicou melhor tal situação que Scott ao afirmar: "Não somos um grupo de celebridades. Nossa força está na maneira como tudo se integra" (Slater, 2003:93).

Tendo decidido não assumir posições de alta administração, a família não quis ir para o outro extremo, demonstrando apenas interesse mar- 
ginal pela empresa. À exceção de Rob, contudo, nenhum outro membro ocuparia posição operacional na direção rotineira. Mesmo assim, os Waltons se manteriam visíveis e atentos. Um deles, além de Rob, sempre seria membro do Conselho de Administração (desde 1992 até hoje é John que ocupa esta posição) e os outros dois poderiam a qualquer tempo assistir às reuniões do mesmo órgão, exceto quando se tratasse de sessões executivas.

Para se manterem informados sobre os assuntos da empresa, todos os Waltons se reúnem três vezes por ano, como família, tendo como tema único a Wal-Mart. As reuniões se estendem por dois ou três dias, às vezes na casa de Helen Walton, em Bentonville, às vezes em algum hotel. Em tais reuniões, os quatro Waltons fazem questão de levar os próprios filhos, até mesmo os adolescentes, pois a família compreende que tem a obrigação não só de se inteirar das últimas ocorrências, mas também de preparar a terceira geração de Waltons para suas possíveis atribuições como donos do negócio.

Tanto para os adultos quanto para as crianças, a reunião representa uma oportunidade para ouvir em primeira mão dos executivos seniores uma série de relatos minuciosos sobre o andamento de vários projetos. Na última reunião descrita por Slater, em 4 de agosto de 2002 , todos os 13 membros da família, com uma única exceção, estavam presentes: Helen Walton, com 82 anos, os quatro filhos e sete de seus oito netos (um estava doente). O sucesso marcante da nova equipe de liderança facilitou a tarefa da família, conforme observa Rob Walton: "Os acionistas não precisam tomar muitas decisões em empresas bem gerenciadas" (Slater, 2003:94).

Para entender como Walton pensou e preparou a sucessão, é necessário verificar como o fundador observava, recrutava e preparava os melhores executivos para assumir os principais postos de comando. Sua estratégia era simples. Dizia: "Aprendi cedo, no ramo de lojas de variedades, que é preciso dar responsabilidade às pessoas, é preciso confiar nelas e, depois, fiscalizá-las" (Walton, 1993:123). Assim fez com muitos dirigentes da empresa, dentre os quais destacou-se David Glass.

Em 1964, Glass dirigiu de Springfield, Missouri, onde trabalhava na Crank Drugs, até Harrison, Arkansas, para a inauguração da segunda loja Wal-Mart. Foi a primeira vez que se encontrou com Sam Walton e não gostou da desorganização de sua loja. Em 1976 Sam convenceu-o a trabalhar com ele e Glass assumiu a função de CFO (principal executivo financeiro). Entre suas novas atribuições incluíam-se processamento de dados, desenvolvimento de sistemas e distribuição. Aos poucos ele 
escalou a hierarquia da Wal-Mart, tornando-se presidente e CEO em 1988.

Assim que Walton morreu, Glass continuou na função, desenvolvendo suas próprias características e qualidades pessoais. "Por causa de Walton, a Wal-Mart foi basicamente um negócio de mercadorias em geral de 1962 a 1988; por causa de Glass, foi um negócio de mercadorias em geral e de produtos alimentícios (itálico nosso) a partir de 1988" (Slater, 2003:99).

Ao contrário de Walton, David Glass não tinha medo de crescer. Para o fundador, crescimento significava endividamento, burocracia e aumento da folha de pagamento, uma despesa atrás da outra. Para David Glass, não havia problema em contrair dívidas para abrir mais lojas Wal-Mart. De 1992 a 1995, Glass aumentou o endividamento a longo prazo da empresa de US $\$ 1,7$ para US $\$ 8,5$ bilhões, usando o dinheiro para construir supercenters, centros de alta tecnologia para a distribuição de alimentos e terrenos para a construção de mais supercenters.

Com a liberdade que passou a desfrutar depois da morte de Walton, Glass tomou algumas decisões de longo alcance sobre tecnologia. Teve a antevisão de compreender que o crescimento da Wal-Mart exigia centros de distribuição do tamanho de depósitos e sistemas de alta tecnologia para o rastreamento de mercadorias. Em 2000, ano em que Glass deixou o cargo de CEO, a Wal-Mart e seus fornecedores intercambiavam eletronicamente pedidos de compra, faturas e outros documentos. Através de sistemas de comunicação por satélite, todas as lojas da Wal-Mart estavam interligadas ao escritório central para o reabastecimento de estoques.

Foi Glass quem transformou a Wal-Mart, de uma cadeia de lojas do interior dos EUA, para uma empresa global entre as maiores do planeta, ao lado de outros símbolos empresariais, como General Motors, Ford e General Eletric.

No final da década de 90 houve um novo processo de sucessão na direção executiva, quando Lee Scott substituiu David Glass. Em 1998, Scott foi promovido de vice-presidente executivo de merchandising a presidente e CEO da Wal-Mart Stores, primeira indicação de que seria o provável sucessor de David Glass. Sucedeu a Don Soderquist, que se tornou vice-presidente sênior. Finalmente, em janeiro de 2000, assumiu o lugar de Glass como CEO e presidente.

A nova equipe de liderança era composta do chairman Rob Walton, do CEO Lee Scott e do responsável pelas lojas, Tom Coughlin. Sob o comando de Scott, a estratégia de Glass, de forte expansão, continuou inalterada, como se pode observar pelos dados dos últimos anos. 
Tabela 3. Wal-Mart: Faturamento líquido por segmentos (em US\$ milhões) - 2001-2003

\begin{tabular}{lcccccc}
\hline Ano & $\begin{array}{c}\text { Lojas } \\
\text { Wal-Mart }\end{array}$ & Sam's Clubs & Internacional & Outros & $\begin{array}{c}\text { Total } \\
\text { companhia }\end{array}$ & $\begin{array}{c}\text { Crescimento } \\
(\mathrm{em} \%)\end{array}$ \\
\hline 2003 & 157,121 & 31,702 & 40,794 & 14,907 & 244,524 & 12 \\
2002 & 139,131 & 29,395 & 35,485 & 13,788 & 217,799 & 14 \\
2001 & 121,889 & 26,798 & 21,100 & 10,542 & 191,329 & 16 \\
\hline
\end{tabular}

Fonte: Wal-Mart. Relatório Anual, 2003:17

\section{Estratégias de ocupação e expansão no mercado internacional}

O sentimento predominante entre os dirigentes da Wal-Mart é o de que sua expansão internacional se dará em cerca de 20 países, sendo que a empresa já atua em quase a metade destes. A estratégia de longo prazo para seu programa internacional é tornar a companhia realmente global. "Isso significa localizar parceiros globais para liderar as diferentes operações internacionais. Significa construir sistemas de distribuição e transporte globais. Significa desenvolver vínculos estreitos entre o lado americano e o lado internacional da empresa" (Slater, 2003:163).

Com este objetivo estratégico definido, a nova equipe dirigente lançou-se na internacionalização. Assim como os supercenters e a venda de gêneros alimentícios transformaram-se em motores de crescimento para a Wal-Mart, no mercado interno, a internacionalização significou literalmente a "descoberta do ouro" além das fronteiras americanas, garantindo a continuidade da expansão.

Uma primeira decisão dizia respeito aos países onde a empresa iria atuar. Após estudos internos e consulta a especialistas, os dirigentes chegaram à conclusão de que "os critérios de escolha dos países deveriam ser a grande base demográfica e uma classe média forte e crescente".

$\mathrm{Na}$ estratégia de expansão além-fronteiras, decidiu-se ocupar os mercados das Américas, da Ásia e da Europa. Durante a década de 1990 o programa internacional da Wal-Mart ostentou crescimento importante, desempenhando papel significativo no quadro financeiro. Em poucos anos ela se tornou o maior varejista do México e do Canadá e o terceiro maior do Reino Unido. Na América do Sul e na Europa, aparece apenas como coadjuvante. "Na Europa, enfrentando custos de mão-de-obra mais altos, sindicatos mais duros e um ambiente regulamentado mais paternalista que nos EUA, a Wal-Mart limitou sua atuação à Inglaterra e Alemanha" (Slater, 2003:149). 
Como foi visto acima, mesmo antes da morte do fundador, a empresa atuava no México. Entretanto, a decisão estratégica de tornar a internacionalização um de seus pilares foi tomada pela equipe dirigente pós-Walton. Uma das primeiras medidas era a escolha de um dirigente que respondesse pela área, fizesse um planejamento e o executasse. O executivo escolhido foi Bob Martin, que entrou na Wal-Mart em 1984 ocupando os cargos de vice-presidente executivo e vice-presidente sênior. Em 1993 David Glass e Rob Walton pediram-lhe para assumir como presidente e CEO da nova divisão internacional.

Sua tarefa era transformar esta divisão num dos principais motores de crescimento da empresa. A expectativa era de que metade do crescimento da Wal-Mart derivasse de gêneros alimentícios, um terço das operações internacionais, e o resto, das lojas Wal-Mart nos EUA.

Martin decidiu iniciar as operações internacionais pelas Américas do Norte e do Sul.Também tinha intenção de entrar na Ásia, tendo a China e Indonésia como pontos de partida e, por fim, entrar na Europa.

A iniciativa que deu início efetivo à internacionalização foi a aquisição das 122 lojas de descontos da canadense Woolco, em 1994. No entanto, entrar num novo mercado não significa imediatamente tornar-se lucrativo. Tanto é que, nos primeiros três anos, 1995-1997, a Wal-Mart do Canadá sofreu prejuízos de tal magnitude que Rob Walton um dia perguntou: "Será que alguém me lembraria por que entramos nesse negócio?" (Slater, 2003:152).

O México não apresentou as mesmas dificuldades, pela maneira como a empresa entrou, exercendo um aprendizado gradativo. A primeira loja foi inaugurada ainda quando Sam Walton vivia, ou seja, em 1991. Em meados da década, as expectativas naquele país eram favoráveis.

Procedimento semelhante foi adotado para a América do Sul, quando, em 1995, a Wal-Mart se instalou nas duas maiores economias da região: Brasil e Argentina. Nestes países, iniciaram-se as operações com poucas lojas próprias, para experimentar e conhecer a cultura local e a forma de melhor atender seus clientes.

Como o mercado asiático tem características próprias e é muito diferente do ocidental, a maneira de ocupá-lo foi via associação com empresas locais. Em 1996, a Wal-Mart constituiu umajoint venture com a intenção de entrar na China e na Indonésia. Em 1999 adquiriu quatro lojas, entrando assim, na Coréia do Sul.

Com lojas próprias ou em parcerias nas Américas e na Ásia, faltava ocupar o mercado europeu. Para tanto, em 30 de dezembro de 1997 a Wal-Mart concluiu a aquisição de 21 hipermercados na Alemanha. 
Uma vez conhecidos os mercados locais, a estratégia de expansão passou a depender das oportunidades que se apresentassem. Várias vezes a empresa, além do crescimento via construção de novas lojas, utilizou as aquisições para um crescimento mais rápido. Foi o caso do México, onde, em 1998, adquiriu o controle do maior varejista, a Cifra, com lojas em todo o país, abrangendo desde a maior cadeia de restaurantes até uma loja de departamento de vestuário, tecidos e utensílios para o lar.

Emjulho de 2004 operava 649 unidades comerciais em 64 cidades, incluindo auto-serviço, lojas de tecidos e restaurantes, empregando 105.365 pessoas. Suas ações são vendidas na Bolsa Mexicana de Valores desde 1977.

Tabela 4. Wal-Mart México: Bandeiras, número de lojas e percentual de vendas — 2004

\begin{tabular}{lccc}
\hline Bandeiras & Número de lojas & \% do total de lojas mexicanas & \% do total de vendas \\
\hline Sam's Clubs & 55 & 8,47 & 29 \\
Bodega & 144 & 22,18 & 29 \\
Wal-Mart & 83 & 12,78 & $\mathbf{2 7}$ \\
Superama & 46 & 7,08 & 6 \\
Suburbia & 50 & 7,70 & 5 \\
Vips & 271 & 41,71 & 4 \\
Total de lojas & 649 & 100 & 100 \\
\hline
\end{tabular}

Fonte: http://www.waltmartmexico.com.mx/acerca.html. Acesso: 12 ago. 2004

Estabelecer e/ou comprar filiais em outros países exige também um tempo de aprendizado e aculturação. A Wal-Mart passou por um duro aprendizado até conhecer o hábito de consumo e a melhor maneira de conquistar os consumidores locais.

Em 1995, quando chegou ao Brasil, vendia equipamentos para esquiar e tacos de beisebol. No Natal do ano seguinte, na tentativa de atrair consumidores, a empresa norte-americana teve de espalhar tendas pelos estacionamentos, pois a quantidade de itens que queria vender não cabia nas lojas (Mattos, 2004:B12).

Emjunho de 1999, Bob Martin deixou o cargo de chefe da divisão internacional, depois de construir um negócio de US\$17 bilhões. Seu substituto foi John Menzer, que entrou na Wal-Mart quatro anos antes como novo Diretor Financeiro. Ao assumir o cargo e após algumas pesquisas, descobriu uma regra prática para a entrada em novos mercados no exterior: demorava-se três anos para gerar lucro e cinco para atingir as metas de retorno. 
Continuando a estratégia de expansão adotada por seu antecessor, uma de suas primeiras metas foi entrar no Reino Unido. Para isto, a Wal-Mart pagou US\$10,8 bilhões pela aquisição da rede de 232 supermercados. O negócio com a ASDA, em junho de 2000, foi a maior compra efetuada pela empresa americana até aquela data.

Após quatro anos de estudo do mercado japonês e de chegar à conclusão de que seria melhor encontrar um sócio local, em 2002, a WalMart pagou US $\$ 46,5$ bilhões por uma participação de $6,1 \%$ na Seiy Lida, quarta maior rede de supermercados do Japão e garantiu a opção de comprar outros dois terços até 2007.

$\mathrm{Na}$ sua internacionalização, a Wal-Mart construiu lojas próprias, associou-se a companhias locais e comprou concorrentes. As aquisições se repetiram na Alemanha, na Inglaterra, no México, no Japão, etc. No Brasil, a empresa crescia devagar, construindo lojas próprias, até chegar a 25, no início de 2004. Em março deste ano, ao pagar US\$300 milhões ao grupo holandês Royal Ahold ${ }^{5}$ pelo Bompreço, mudou de estratégia e passou a disputar o mercado nacional com seus principais concorrentes.

A aquisição alterou as posições entre as maiores empresas do setor, possibilitando uma economia de escala, com a qual "a gigante deve aumentar a tensão, já grande, entre indústria e varejo. Nos EUA seu forte poder de barganha é temido por todos os fornecedores. Pela internet, a rede consegue comprar o que quiser pelo menor preço do mundo" (Diniz, 2004:51).

Tabela 5. Wal-Mart antes e depois da compra do Bompreço - 2004

\begin{tabular}{lcccc}
\hline Situação & $\begin{array}{c}\text { Faturamento } \\
\text { (em R\$ bilhões) }\end{array}$ & $\begin{array}{c}\text { Posição } \\
\text { no ranking }\end{array}$ & Número de lojas & $\begin{array}{c}\text { Faturamento } \\
\text { (em R \$ bilhões) }\end{array}$ \\
\hline Antes & 1,7 & $6^{\circ}$ & 25 & 1,7 \\
Depois & 5 & $3^{\circ}$ & 143 & 5,0 \\
\hline
\end{tabular}

Fonte: Wal-Mart/Roland Berger. Citado por Diniz, 2004:49.

O Bompreço, almejado pelo Carrefour e pelo Pão de Açúcar, além da

O grupo Ahold chegou ao Brasil em 1996, associando-se ao Bompreço, com base em Pernambuco. No ano seguinte comprou a rede baiana Supermar.Em 2001 adquiriu a sergipana G. Barbosa e em 2002 comprou nove das 16 lojas da maranhense Lusitana. A expansão levou o Ahold a deter cerca de $70 \%$ do mercado nordestino e atingir vendas de 4,1 bilhões de reais em 2002, empregando 23.510 pessoas (Mano, $2003: 65)$. 
Wal-Mart, fez com que aumentasse a disputa por redes regionais. A WalMart, com esta aquisição, passou a ser a terceira maior do país, como se pode observar pela tabela anterior.

Uma vez estabelecida nestes países, a Wal-Mart precisava compreender com rapidez as preferências dos clientes locais, como abastecer as lojas com eficácia e como lidar com os fornecedores. As novas lojas nos países estrangeiros precisavam inovar para serem competitivas, descobrindo, muitas vezes, maneiras novas e mais práticas de funcionamento que, na seqüência, foram levadas para os próprios EUA.

$\mathrm{Na}$ arrumação das prateleiras foi utilizado o método brasileiro de reabastecimento, pelo qual os empregados repõem os estoques por trás de paredes internas, sem atrapalhar a movimentação dos clientes.

As lojas norte-americanas aproveitaram a experiência da venda de sapatos canadense, na forma de apresentá-los nas caixas e exibi-los por estilo ao invés de por tamanho. Para a exibição de vinhos, seguiu-se prática oriunda do México, com nova forma de mostruário. Também no layout de gêneros alimentícios a inovação é mexicana.

Por fim, na venda de roupas, trata-se de uma linha desenvolvidas no Reino Unido que também está sendo vendida nas lojas Wal-Mart nos EUA e em outros lugares.

Em meados de 2004 a Wal-Mart estava presente em nove países fora dos EUA, totalizando 1.355 lojas (ainda não computadas as do Bompreço, adquiridas no Brasil no início do ano). Deve-se salientar que atua também no Japão, mas suas lojas não aparecem na contagem, uma vez que a empresa ainda é sócia minoritária na Seiy Ltda.

Pelas últimas declarações de seus dirigentes e pelos movimentos de ocupação do mercado internacional, percebe-se que as estratégias acima descritas estão sendo colocadas em prática. John Menzer, atual responsável pelos negócios internacionais, "diz que está de olho em todas as chances de novas compras no Brasil" (Mattos, 2004:B12). Afirma ainda que China, Índia, Rússia, México e Brasil são países vistos como oportunidades de expansão.

Apesar de sua crescente presença em dez países fora das fronteiras americanas, o desafio da internacionalização ainda não foi atingido. Estudos da McKinsey (Diniz, 2004) mostram que, embora gigante, a Wal-Mart precisa crescer muito fora dos EUA, pois entre as grandes empresas de varejo ela é a menos internacionalizada. Apenas 13,3\% de suas receitas vêm de fora do seu país de origem, ante $31,1 \%$ no caso do Carrefour, uma das mais internacionalizadas. 


\begin{tabular}{|c|c|c|c|c|c|c|}
\hline País & $\begin{array}{l}\text { Ano da } \\
1^{\text {a }} \text { loja }\end{array}$ & $\begin{array}{l}\text { Lojas de } \\
\text { desconto }\end{array}$ & Supercenters & SAM'S Clubs & $\begin{array}{c}\text { Mercados } \\
\text { de vizinhança }\end{array}$ & Total \\
\hline EUA & $1945 / 1962$ & 1.478 & 1.471 & 538 & 64 & 3.551 \\
\hline México & 1991 & $487 * *$ & 83 & 53 & & 623 \\
\hline Porto Rico & 1991 & 9 & 3 & 9 & $32 *$ & 53 \\
\hline Canadá & 1994 & 231 & 4 & & 235 & \\
\hline Brasil & 1995 & & 13 & 10 & $2 *$ & 25 \\
\hline Argentina & 1995 & & 11 & & & 11 \\
\hline China & 1996 & & 28 & 4 & 2 & 34 \\
\hline Alemanha & 1997 & & 92 & & & 92 \\
\hline Coréia & 1999 & & 15 & & & 15 \\
\hline Reino Unido & 2000 & $255^{++}$ & 12 & & & 267 \\
\hline Total Internac. & & 982 & 257 & 80 & 36 & 1.355 \\
\hline Total Geral & & 3.460 & 1.728 & 618 & 100 & 4.906 \\
\hline
\end{tabular}

* Brasil inclui lojas Todo Dia.

** México inclui 140 Bodegas, 52 Suburbias, 44 Superamas, 251 Vips.

+ Porto Rico inclui 32 Amigos.

+ Reino Unido inclui 253 ASDA Stores e 2 George Stores.

Fonte: Dados disponíveis em http://www.walmart.com. Acesso: jul. 2004.

\section{Considerações finais}

Estudar a história da Wal-Mart é voltar para a sociedade americana do pós-Segunda Guerra e localizar-se no sudoeste do país, nas pequenas cidades do interior. É também buscar explicações para o sucesso de uma empresa que acompanhou a evolução da economia norte-americana ao longo do período de crescimento, com fortes mudanças tecnológicas, de hábitos alimentares e formas de consumo.

Sam Walton iniciou a carreira como franqueado de lojas de miudezas, nas quais testou um modelo, estabelecendo relação direta com os fornecedores, buscando o preço mais baixo possível e repassando-o integralmente aos consumidores. Estabeleceu o conceito de "preços baixos em todos os produtos e todos os dias". Das lojas de variedades passou aos supermercados, em forte expansão nos EUA dos anos 195060, muito mais lucrativos que as lojas tradicionais.

Buscando novidades entre os concorrentes, Sam lançou, no final dos anos 1980 os hypermart, que não trouxeram os resultados esperados, mas evoluíram para os supercenters, que representaram o impulso definitivo na evolução da Wal-Mart a partir dos anos 90. Esta busca de formas adaptadas para os consumidores de cada local levou aos atuais quatro 
formatos de lojas: Lojas de descontos, Supercenters, Sam's Clubs, Mercados de Vizinhança.

Ao se transformar na maior rede de varejo dos EUA, utilizou sua força e escala de venda para pressionar os fornecedores a diminuírem constantemente os preços. "Alguns economistas dizem que a rede, sozinha, reduziu em $1 \%$ a inflação nos últimos anos, economizando bilhões de dólares para os consumidores" (Greenhouse, 2004:A28). Os críticos, por sua vez lembram que "o Wal-Mart é certamente um modelo para o capitalismo do século XXI, mas um capitalismo que se assemelha cada vez mais ao de cem anos atrás", sobretudo pelos baixos salários pagos, os fracos e/ou inexistentes planos de assistência aos funcionários, o esforço para anular a atuação sindical e a pressão sobre os fornecedores.

Um desafio em construção, a partir do início da década de 1990 foi a internacionalização. Em pouco mais de uma década, conseguiu estabelecer-se numa dezena de países, nas Américas, Ásia e Europa. Os executivos pensam em dobrar o número de nações, sempre nos mesmos continentes, levando em conta a classe média, a população e a capacidade de consumo.

Chegar a outros países exige um tempo de aprendizado, tanto para o retorno financeiro como para entender particularidades as culturas locais. Uma vez dominada a lógica de funcionamento dos países, as multinacionais adquirem uma capacidade de aprendizagem fundamental, conseguindo levar boas idéias locais para o cenário mundial, com as devidas adaptações.

Já em vida, Sam Walton preocupou-se em deixar encaminhado o processo de sucessão. Alguns anos antes de sua morte, passou seu próprio cargo de CEO a um executivo de carreira dentro da empresa e não pertencente à família. Depois de sua morte, adotou-se o modelo de administração mista, com Robson e John ocupando cargos no Conselho de Administração, enquanto os maiores postos de comando no Conselho Executivo são ocupados por profissionais de carreira, de fora da família.

Esta nova equipe de direção transformou de vez a Wal-Mart de empresa do interior para uma empresa nacional e internacional. Foi também a equipe pós-Walton que preparou a Wal-Mart em tecnologia, logística, equipe central e comunicações, que deram suporte ao forte crescimento dos últimos anos.

A perspectiva é de mais expansão, tanto no mercado interno como em construção de lojas próprias e em aquisições em cerca de vinte 
países no mercado internacional. O avanço dos últimos anos e a maneira como a empresa se estruturou internamente possibilitam visualizar um novo período de crescimento, assim como o acirramento na disputa do varejo internacional.

\section{Referências bibliográficas}

C H A N D LER, Alfred. Stratégies et structures de l'entreprise. Paris: Les éditions d'organisation, 1972 ( $1^{*}$ ed. americana, 1962).

CHANDLER, Alfred. Ensaios para uma teoria histórica da grande empresa (Org. Thomas K. McCraw). Rio de Janeiro: Fundação Getulio Vargas, 1998.

DALlA COSTA, Armando João; PURKOTE, Glacy Terezinha; SANTOS, Edivalado Pereira dos. "Concorrência e desafios entre os supermercados curitibanos com a chegada das multinacionais do varejo". Revista da Sociedade Brasileira de Pesquisa Histórica. Curitiba: SDPH, no 20, 2001, pp.119-136.

DALlA COSTA, Armando João; LUZ, Adão Eleutério da. "Sucessão e sucesso nas empresas familiares: o caso do grupo Pão de Açúcar". Anais do V Congresso Brasileiro de História Econômica e VI Conferência Internacional de História de Empresas. CaxambuMG, 7 a 10 de setembro de 2003, 28 pp. (Edição eletrônica - CD).

DALlA COSTA, Armando João. "A importância da logística no varejo brasileiro: o caso do Pão de Açúcar". Cadernos da Escola de Negócios da Unibrasil. Curitiba: UniBrasil, $\mathrm{n}^{\circ} 2$, Jan/Jun. 2004, pp. 65-84.

DIN1Z, Daniela."O bicho-papão acordou. Ao comprar o Bompreço a Wal-Mart dá sinais de que vai entrar para valer nojogo do varejo no Brasil". Revista Exame. São Paulo: Abril, ano 38, ed. 813, $\mathrm{n}^{\circ}$ 5,17 de março de 2004, pp. 48-50.

GERSICK, Kelin E. et. al. De geração para geração. Ciclos de vida das empresas familiares. 2. ed. São Paulo: Negócio Editora, 1997.

GREENHOUSE, Steven. "Wal-Mart intriga intelectuais dos EUA. Sociólogos e historiadores fazem simpósio só para tentar entender o fenômeno da ultrapoderosa cadeia varejista". Jornal Folha de S.Paulo. Caderno Mundo, 18 de abril de 2004, p. A 28 .

http://www.abras.org.br Site da Associação Paranaense de Supermercados.Várias consultas em 2004.

http://.www.abrasnet.com.br Site da Associação Brasileira de Supermercados.Várias consultas em 2004.

http://www.asda.com Site da Wal-Mart na Inglaterra.Várias consultas em 2004.

http://www.walmart.com Site com dados dos Estados Unidos e da empresa de modo geral.Várias consultas em 2004.

http://www.wal-mart.com.ar Várias consultas em 2004.

http://www.walmart.com.brVárias consultas em 2004.

http://www.walmartcanada.ca Várias consultas em 2004.

http://www.wal-martchina.com Várias consultas em 2004. 
http://www.walmartgermany.de Várias consultas em 2004.

http://www.walmartkorea.com Várias consultas em 2004.

http://www.walmartmexico.com.mx Várias consultas em 2004.

http://www.walmartpr.com Site de Porto Rico.Várias consultas em 2004.

LUZ, Cátia. "Indústria do desconto. Empresas se adaptam à queda de renda dos brasileiros e lançam produtos cada vez mais simples e baratos", in Revista Época. Rio de Janeiro: Ed. Globo, n³16, 7 de junho de 2004, pp. 46-48.

MANO, Cristiane. "Quem vai se dar bem? Como a venda do Bompreço, do grupo holandês Royald Ahold, deverá desencadear um novo movimento de consolidação do setor de supermercados no Brasil". Revista Exame. São Paulo: Abril, ano 37, ed. $799, \mathrm{n}^{\circ} 17,20$ de agosto de 2003, pp. 64-67.

MARTINS, Ives Gandra da Silva; MENEZES, Paulo Lucena de; BERNHOEFT, Renato (Coord.). Empresas familiares brasileiras. Perfil e perspectivas. São Paulo: Negócio Editora, 1999.

MATTOS, Adriana. "Wal-Mart admite erros e faz planos no Brasil". Rede americana diz que país está na lista de investimentos e que pretende manter preços até 7\% inferiores aos da concorrência. Jornal Folha de S.Paulo. Caderno Dinheiro, 6 de junho de 2004, p. B 12 .

NAPOLITANO, Giuliana. "O Banco do Dr. Abílio. Pão de Açúcar segue tendência mundial e faz parceria com o Itaú para financiar clientes". Revista Exame. São Paulo: Abril, ano 38, ed. 823, n 15, 4 de agosto de 2004, pp. 94-95.

SCOTT, Lee. "The everyday price cutter". The Economist.Vol. 372, n. 8.392 (First published in Sepetember 1843), September 11 th 2004, p. 62.

SLATER, Robert. Wal Mart. Como a nova geração de líderes transformou o legado de Sam Walton na empresa \# 1 do mundo. Rio de Janeiro: Campus, 2003.

WAL-MART. Relatórios Anuais 1972-2004. Disponíveis em http://www.walmart.com. Várias consultas em 2004.

W Alton, Sam; HUEY, John. Made in America. 4. ed. Rio de Janeiro: Campus, 1993. 